\title{
A novel enzymatic biosensor for detection of intracellular hydrogen peroxide based on 1-aminopyrene and reduced graphene oxides
}

\author{
NA ZOU ${ }^{\mathrm{a}, \mathrm{b}}$, XIANYONG WEI ${ }^{\mathrm{a}, \mathrm{c}, *}$, ZHIMIN ZONG ${ }^{\mathrm{a}}, \mathrm{XIN} \mathrm{LI}^{\mathrm{b}}, \mathrm{ZHAOXIA} \mathrm{WANG}^{\mathrm{b}}$ and \\ XUELIANG WANG ${ }^{\mathrm{b}, *}$ \\ ${ }^{a}$ Key Laboratory of Coal Processing and Efficient Utilization, Ministry of Education, China University of Mining \\ and Technology, Xuzhou 221116, Jiangsu, China \\ ${ }^{\mathrm{b}}$ School of Chemistry and Chemical Engineering, Heze University, Heze 274015, Shandong, China \\ ${ }^{\mathrm{c}}$ State Key Laboratory of High-Efficiency Coal Utilization and Green Chemical Engineering, Ningxia University, \\ Yinchuan 750021, Ningxia, China \\ E-mail: wei_xianyong@163.com; qust-1977wxl@163.com
}

MS received 3 December 2018; revised 29 January 2019; accepted 10 February 2019; published online 21 March 2019

\begin{abstract}
An electrochemical sensor for hydrogen peroxide $\left(\mathrm{H}_{2} \mathrm{O}_{2}\right)$ detection was established using 1aminopyrene (AP) as a linker between horseradish peroxidase (HRP) and reduced graphene oxides (rGO) modified glassy carbon electrode. The AP can combine with HRP via a covalent bond and combine with rGO via $\pi-\pi$ conjugation. The covalent bond linkages can prevent the enzymes leaching of the enzymes and the $\pi-\pi$ conjugate combination can facilitate electrons transfer, which plays synergistic effects to improve the performance of this sensor. The electrochemical activity of the HRP-AP/rGO was described by cyclic voltammetry, alternating current impedance and amperometric techniques. Under the optimal conditions, the biosensor showed a wide linear range from $1.5 \mu \mathrm{M}$ to $28.5 \mu \mathrm{M}$ and a low detection limit of $0.5 \mu \mathrm{M}$ with good stability and high selectivity, confirming that the sensor is well-suited for the detection of $\mathrm{H}_{2} \mathrm{O}_{2}$ during biological processes.
\end{abstract}

Keywords. Enzymatic biosensor; 1-aminopyrene; reduced graphene oxides; hydrogen peroxide; horseradish peroxidase.

\section{Introduction}

$\mathrm{H}_{2} \mathrm{O}_{2}$ is the most stable and abundant reactive oxygen species in an organism, and present in many biological processes. ${ }^{1}$ Quantitative detection of $\mathrm{H}_{2} \mathrm{O}_{2}$ has important scientific significance for understanding intracellular signal transduction and realizing the normal function of cells. $\mathrm{H}_{2} \mathrm{O}_{2}$ can also be used as an intermediate biomolecule in other biological assays, including indirect detection of glucose, ${ }^{2}$ and quantitative analysis of other biomarkers ${ }^{3,4}$ and phenol ${ }^{5,6}$ coupled with specific enzymes capable of depleting or producing $\mathrm{H}_{2} \mathrm{O}_{2}$. The concentration of $\mathrm{H}_{2} \mathrm{O}_{2}$ in these processes is very low, therefore, traditional non-enzymatic redox methods ${ }^{7-15}$ are difficult to meet the actual detection requirements as their low catalytic activity. Additionally, the non-enzymatic method usually involves a redox-active medium, which may make the

\footnotetext{
*For correspondence
}

observed electrochemical response not relate to $\mathrm{H}_{2} \mathrm{O}_{2}$ concentration.

All chemical reactions that occur in the organism are enzymatic reactions, enzymes are efficient, specific catalysts, and the efficient catalytic properties of enzymes are obtained by forming clathrates with the substrate. In view of the rapid development of biotechnology, immobilizing enzymes on solid substrates for biosensing, and developing heterogeneous enzyme biosensors is a promising research direction and one of the hottest topics in analytical chemistry. After the oxidoreductase is immobilized on the surface of the biocompatible solid electrode, the signal generated by their direct interaction with the specific analyte in the solution can show enhanced electrochemical activity, resulting in higher sensitivity and better selectivity of electrochemical measurement.

Many enzymatic immobilization methods have been reported, including entrapment, ${ }^{16-18}$ adsorption, ${ }^{19-21}$ covalent binding, ${ }^{22,23}$ and cross-linking. ${ }^{24}$ The choice of these methods has a profound effect on the direct 
electron transfer of proteins and the overall stability of the sensor. On the one hand, the entrapped material and the adsorbate used to immobilize the enzyme have poor conductivity which extends the distance between the redox-active center and the electrode, and hinders the direct electron transfer between the redox-active protein and the electrode. ${ }^{25}$ On the other hand, the immobilization of the substrate by the matrix is not strong enough and there will be unavoidable enzyme leaching, which will affect the stability of the biosensor. ${ }^{26}$ What is more, it may also cause multiple sites of the enzyme to bind to the carrier, destroying the natural conformation of the enzyme, significantly reducing the activity of the immobilized enzyme. Therefore, orientation and high-efficiency enzyme immobilization methods have become the key to study sensors.

In general, the covalent attachment of an enzyme molecule to a surface is more favorable than physical adsorption in order to avoid the severe exudation of enzymes from the surface. ${ }^{27}$ Direct electrical contact between the redox protein and the electrode has been improved by the use of a well-conductive matrix such as polycationic self-assembled monolayers, conducting polymer hydrogels, and carbon paste immobilization, all of which provide electronic conduction pathway between protein and electrodes. ${ }^{23}$ By interaction of protein and electrode, electrons can be transferred directly between the enzyme and the electrode, and direct detection of the active site of the redox protein can be obtained. This method does not require redox mediators and is well-suited for the study of electron transfer mechanisms and greatly simplifies device fabrication.

HRP is a heme-containing protein widely distributed in the plant kingdom. It is a glycoprotein formed by the combination of a colorless enzyme protein and a brown iron porphyrin. In biosensing analysis, HRP is widely used to detect hydrogen peroxide, glucose, metal ions, DNA and other biological molecules. ${ }^{28-31}$ Like most water-soluble enzymes, immobilization of HRP is a necessary way to realize the application value. 1-Aminopyrene (1-AP) is a bifunctional molecule with a pyrenyl group and an amino functional group. It has been successfully used as a linker to immobilize enzyme to fabricate electrochemical sensors. ${ }^{22,33}$

In this work, HRP was immobilized on the electrode surface to detect $\mathrm{H}_{2} \mathrm{O}_{2}$ in the biological process. The glycosyl group on the surface of HRP can be used as an immobilization site. Firstly, HRP is covalently bonded with $1-A p$, and then they $\pi-\pi$ conjugated to the support of rGO to establish a newly reduced graphene oxide/Aminopyrene/enzyme immobilization system. This novel immobilization method utilizes the excellent electronic conductivity of rGO and 1-Ap, combine covalent bonding with conjugation linkages to prevent the leaching of enzymes to achieve the direct transfer of electrons between the active centers of proteases and the electrodes. Such firm enzyme electrodes are particularly attractive for in vivo applications where leaching of diffusional mediators is to be avoided. The resulting electrodes will offer high current outputs, fast response and stabilize the mediator to electrode surfaces.

\section{Experimental}

\subsection{Materials and reagents}

HRP was purchased from Shanghai Yuanye Biotechnology Co., Ltd., and rGO was obtained from Shandong Yuhuang New Energy Technology Co., Ltd., 1-AP was purchased from Beijing Bellingway Technology Co., Ltd., and all the other reagents were analyzed Pure, the water used in all experiments is ultrapure water.

\subsection{Preparation of HPR-AP/rGO hybrids}

The preparation of enzyme electrodes is presented in Scheme 1. The electrochemical enzyme biosensor consists of a modified GCE, which is coated with a mixture of HPR$\mathrm{AP} / \mathrm{rGO}$. The mixture is a stable suspension, fabricated by a conjugation between rGO and 1-AP and covalent bonding between 1-AP and HRP. The specific procedure is as follows. Firstly, $0.0020 \mathrm{~g}$ rGO was ultrasonically dispersed in $0.5000 \mathrm{~mL}$ ethanol for $2 \mathrm{~h}$ and $0.0210 \mathrm{~g}$ AP was dissolved in $0.5000 \mathrm{~mL}$ ethanol. Then they were mixed together for $1 \mathrm{~h}$ on an air bath shaker and made to stand for one day. After that, the suspension experienced several washings with ethanol, centrifugation, and finally drying in the oven, marked as AP/rGO. Then, the procedure was followed by the attachment of the enzyme and $\mathrm{AP} / \mathrm{rGO}$, using glutaraldehyde (GA) as a cross-linker. $2.0 \mathrm{mg}$ of newly made $\mathrm{AP} / \mathrm{rGO}$ complex was dispersed in $1.000 \mathrm{~mL}$ of PBS buffer solution, and then $0.1000 \mathrm{~mL}$ of a $5 \mathrm{wt} \%$ aqueous solution of GA was added. The mixture was shaken for $30 \mathrm{~min}$ to make sure that GA is connected to the amino group on the AP. Then $200 \mu \mathrm{L}$ of $1 \mathrm{mg} / \mathrm{mL}$ HRP was added to the solution which continued to oscillate for $30 \mathrm{~min}$ to complete the reaction. At this time, HRP were successfully attached to the $\mathrm{AP} / \mathrm{rGO}$ and a homogeneous dispersion was obtained (HPR-AP/rGO). The prepared hybrids were stored in a refrigerator at $4{ }^{\circ} \mathrm{C}$ before use. Attenuated total internal reflectance fourier transform infrared (ATR-FTIR) spectroscopy was used to characterize the modified materials. They were all recorded on a thermo scientific nicolet Tiso50 FTIR spectrometer. 


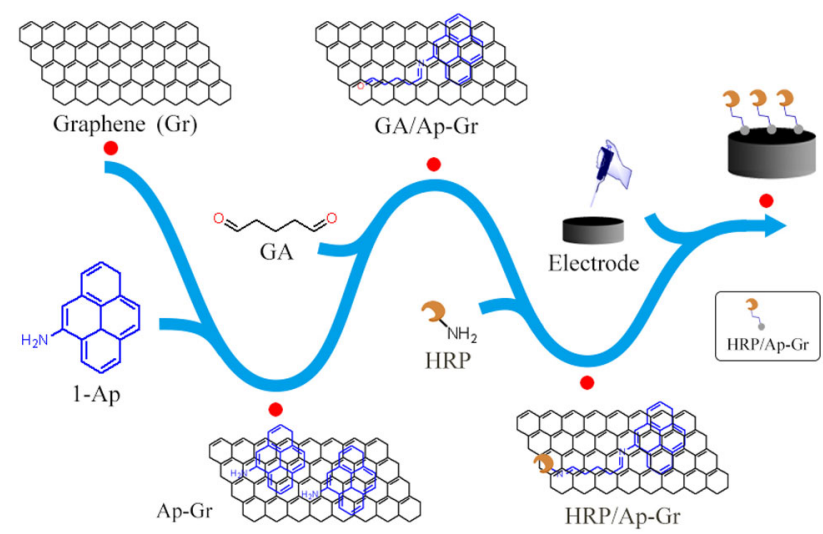

Scheme 1. Preparation of HRP-AP/rGO modified enzyme electrode.

\subsection{Electrochemical measurements}

Electrochemical measurements were performed with a CHI660D electrochemical working station (CH Instruments Inc, China). The three-electrode system was used for all electrochemical experiments, employing a modified glass carbon electrode (GCE) (3 $\mathrm{mm}$ in diameter) as working electrode, a platinum wire as a counter electrode and a saturated calomel electrode (SCE) as a reference electrode at room temperature of about $20^{\circ} \mathrm{C}$. Before the glassy carbon electrode was used, the aluminium oxide powder having a particle size of 1.0, 0.3 and $0.05 \mu \mathrm{m}$ was used for polishing, followed by ultrapure water, ethanol, and ultrapure water washing. After that, $5 \mu \mathrm{L}$ solution of the HPR-AP/rGO was dipped in the freshly pretreated GCE surface and dried at room temperature overnight.

For comparison, $\mathrm{rGO} / \mathrm{GCE}$, and $\mathrm{AP} / \mathrm{rGO} / \mathrm{GCE}$ electrodes were fabricated in the same way: firstly, $\mathrm{AP} / \mathrm{rGO}$ or $\mathrm{rGO}$ was ultrasonically dispersed in ultrapure water before drop coating onto the electrode. Then $5 \mu \mathrm{L}$ of the suspension was applied dropwise onto the electrode. After a thorough rinse with water, the resulting electrode was immersed in $1.0 \mathrm{mM}$ $\left[\mathrm{Fe}(\mathrm{CN})_{6}\right]^{3-/ 4-}$ a solution containing $0.1 \mathrm{M} \mathrm{KCl}$ for cyclic voltammograms and alternating current $(\mathrm{AC})$ impedance detection.

Successive cyclic voltammograms were performed in the potential range of $-0.3 \mathrm{~V}$ to $+0.6 \mathrm{~V}$ at a scan rate of $80 \mathrm{mVs}^{-1}$. The AC impedance experiment was carried out with frequencies ranging from $0.1 \mathrm{~Hz}$ to $100 \mathrm{kHz}$. Amperometric experiments were performed in a stirred cell with the successive addition of $5 \mu \mathrm{L} 1.5 \mathrm{mM} \mathrm{H}_{2} \mathrm{O}_{2}$ into $5.0 \mathrm{~mL}$ of supporting solution, while the electrode potential was set at $-100 \mathrm{mV}$. All experimental solutions were deoxygenated by bubbling ultrapure argon for 15 min and maintained under an argon atmosphere during the course of the experiments.

\section{Results and Discussion}

\subsection{Characterization of HPR-AP/rGO hybrids}

Attenuated total internal reflectance Fourier transform infrared (ATR-FTIR) spectroscopy was used to characterize the modified materials as shown in Figure 1.

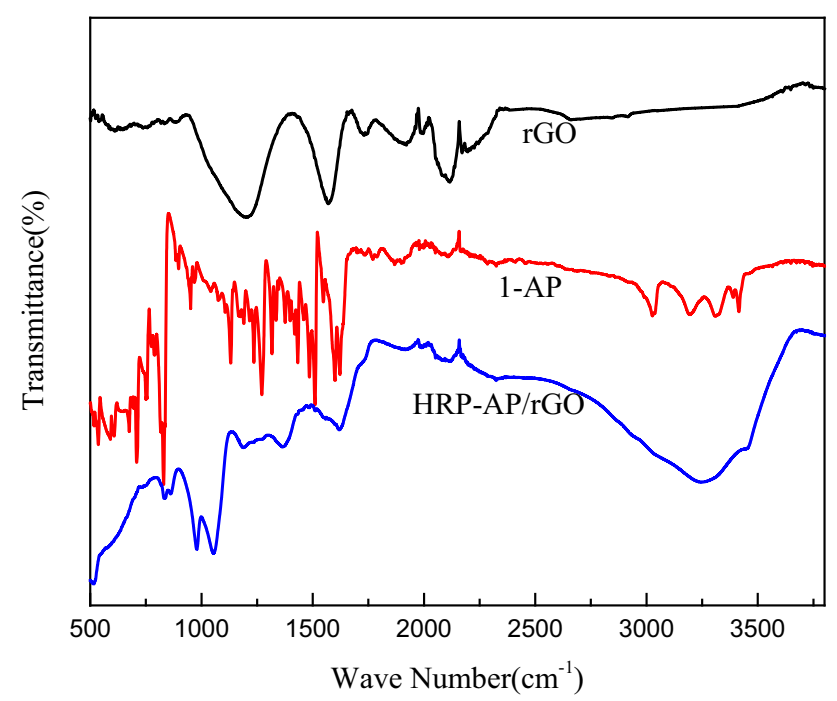

Figure 1. ATR-FTIR spectra of rGO, 1-AP and HRP-AP/ rGO.

By comparing the spectra of $\mathrm{rGO}, 1-\mathrm{AP}$ and with that of HPR-AP/rGO hybrids, the absorption peak of amino groups $\left(3300 \mathrm{~cm}^{-1}\right)$ increased significantly in the spectra of HPR-AP/rGO hybrids, which confirmed that HPR has been successfully connected to the hybrids. Two new peaks appear near $1000 \mathrm{~cm}^{-1}$ can attribute to $\pi-\pi$ interaction of rGO and 1-AP.

\subsection{Electrochemical activity of different electrodes}

Cyclic voltammetry (CV) and electrochemical impedance spectroscopy (EIS) were employed to characterize the electrochemical processes of the different electrodes during the preparation of this sensor. Figure 2 exhibited the CV curves of the bare GCE and different materials modified GCE in the presence of $1.0 \mathrm{mM}\left[\mathrm{Fe}(\mathrm{CN})_{6}\right]^{3-/ 4-}$. As we can see, the blank GCE displayed an anodic peak at $0.185 \mathrm{~V}$ and the corresponding cathodic peak at $0.261 \mathrm{~V}$, which are attributed to the $\mathrm{Fe}(\mathrm{III}) / \mathrm{Fe}$ (II) redox couple of $\left[\mathrm{Fe}(\mathrm{CN})_{6}\right]^{3-/ 4-}$. Under the identically experimental conditions, both $\mathrm{rGO} / \mathrm{GCE}$ and $\mathrm{AP} / \mathrm{rGO} / \mathrm{GCE}$ displayed stronger redox peaks. And the response currents obtained were much bigger than that of obtained at bare GCE, which showed that the $\mathrm{rGO}$ and $\mathrm{AP} / \mathrm{rGO}$ can facilitate the electron transfer of $\left[\mathrm{Fe}(\mathrm{CN})_{6}\right]^{3-/ 4-}$ reduction. When HRP was covalently attached to the electrode, $\mathrm{CV}$ curves displayed poor electrochemical activity with an inferior reduction current response. In contrast to the peak current obtained from $\mathrm{rGO} / \mathrm{GCE}$ and $\mathrm{AP} / \mathrm{rGO} / \mathrm{GCE}$, it may, therefore, be attributed to the introduction of HRP into the AP/rGO matrix owing to HRP that can hinder direct electron transfer. This also further proved the successful covalently attachment of HPR on AP. 


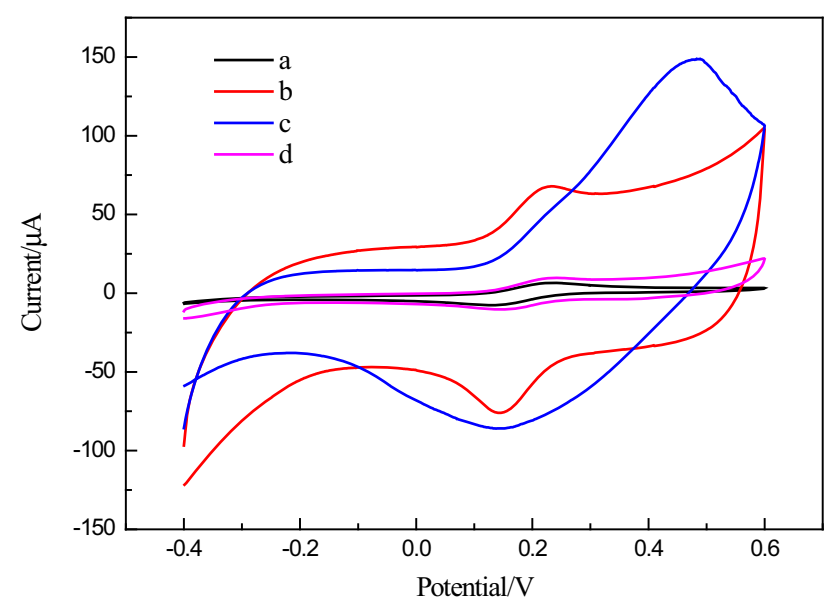

Figure 2. Cyclic voltammograms of (a) bare GCE, (b) rGO/GCE, (c) AP/rGO/GCE and (d) HRP-AP/rGO/GCE in $1.0 \mathrm{mM}\left[\mathrm{Fe}(\mathrm{CN})_{6}\right]^{3-/ 4-}$ at the scan rates of $100 \mathrm{mV} / \mathrm{s}$.

Above all, when AP/rGO was uniformly distributed on GCE, the AP/rGO would serve as highly conductive substrates to interconnect the GCE for efficient electron transfer. Thus, the obtained AP/rGO/GCE could not only have good conductivity but also benefit from AP's abundant amino functional groups to connect the HPR, bringing about more active sites for $\mathrm{H}_{2} \mathrm{O}_{2}$ electrocatalytic reduction. More importantly, the connection force between the electrodes and HRP in HRP-AP/rGO/GCE hybrids is in conjugation and covalent bonded. They are much better than the adsorption or entrapment, and can obviously increase the stability of the electrochemical sensor. The above factors make the HRP-AP/rGO/GCE hybrids to be a good electrochemical sensor for detecting trace quantities of $\mathrm{H}_{2} \mathrm{O}_{2}$.

The immobilization of HRP and AP/rGO on the GCE is also demonstrated by EIS. Figure 3 shows the EIS for (a) bare GCE, (b) rGO/GCE, (c) AP/rGO/GCE and (d) $\mathrm{HRP}-\mathrm{AP} / \mathrm{rGO} / \mathrm{GCE}$, recorded in $1.0 \mathrm{mM}\left[\mathrm{Fe}(\mathrm{CN})_{6}\right]^{3-/ 4-}$ as the background electrolyte with a swept frequency range from 0.1 to $10^{5} \mathrm{~Hz}$. The measured EIS were fitted applying the classical Randle's electronic equivalent circuit. In accordance with the traditional Faradic impedance spectra, the obtained EIS were composed of a semicircle portion and a straight-line portion respectively at higher and lower frequencies. The semicircle portion was bound up with an electron transfer-limited course and the straight-line portion was related to diffusion procedure. The diameter of the semicircle in EIS indicates the electron transfer resistance $\left(R_{\mathrm{et}}\right)$ at the electrode surface. ${ }^{9}$ The $R_{\text {et }}$ changes in the following sequence: bare GCE $<\mathrm{HRP}-\mathrm{AP} / \mathrm{rGO} / \mathrm{GCE}<$ $\mathrm{rGO} / \mathrm{GCE}<\mathrm{AP} / \mathrm{rGO} / \mathrm{GCE}$. These results denote that $\mathrm{AP} / \mathrm{rGO}$ could accelerate electron transfer between the

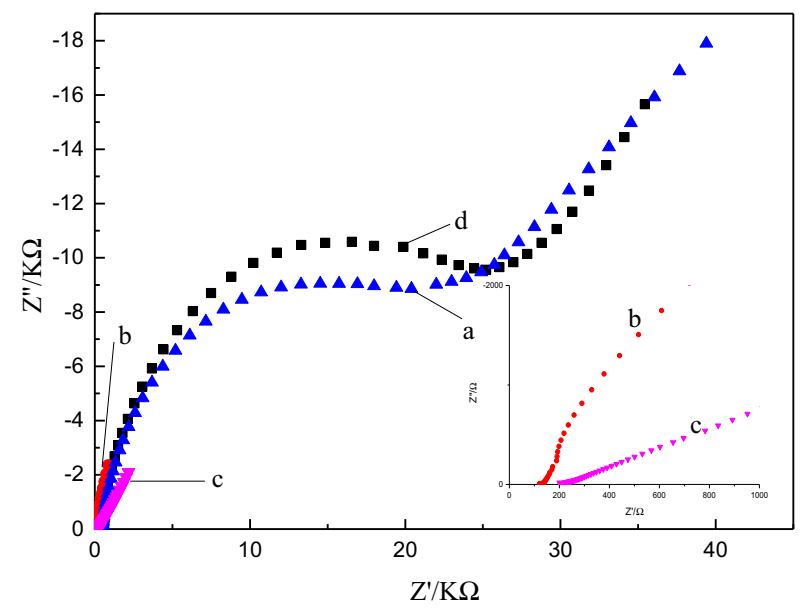

Figure 3. Electrochemical impedance spectra of (a) bare GCE, (b) $\mathrm{rGO} / \mathrm{GCE}$, (c) $\mathrm{AP} / \mathrm{rGO} / \mathrm{GCE}$ and (d) $\mathrm{HRP}-\mathrm{AP} / \mathrm{rGO} / \mathrm{GCE}$ recorded at the open circuit potential in $1.0 \mathrm{mM}\left[\mathrm{Fe}(\mathrm{CN})_{6}\right]^{3-/ 4-}$.

electrode surface and $\left[\mathrm{Fe}(\mathrm{CN})_{6}\right]^{3-/ 4-}$ electrochemical probe, and also verify that HRP is successfully and firmly attached to the electrode through conjugation and covalent bonding. This showed good agreement with the previous CV researches. The perfect property of HRP-AP/rGO/GCE confirmed by EIS made it a competitive material for multiple electrochemical applications, specifically for electrochemical biosensors desirable for $\mathrm{H}_{2} \mathrm{O}_{2}$ detection.

\subsection{Optimization of parameters}

In order to further study the electrocatalytic activity of HRP-AP/rGO hybrids towards $\mathrm{H}_{2} \mathrm{O}_{2}$ and excavate its possible application potential, we investigated the effect of experimental conditions. The effect of $\mathrm{pH}$ of buffer solution on the biosensor response for $\mathrm{H}_{2} \mathrm{O}_{2}$ was examined in the PBS solutions at various $\mathrm{pH}$ values. The results were analyzed in terms of the response current of the biosensor for a $0.5 \mathrm{mM} \mathrm{H}_{2} \mathrm{O}_{2}$ buffer solution. The maximum response was reached at about $\mathrm{pH}$ 7.0. Therefore, the PBS buffer at $\mathrm{pH} 7.0$ was used in the following experiments.

As shown in Figure 4, the effect of the applied potential on the biosensor response for a $0.5 \mathrm{mM} \mathrm{H}_{2} \mathrm{O}_{2}$ solution was investigated through the amperometric measurement. As we can see, the response currents of the biosensor decrease as the polarized potential shifts from $-0.3 \mathrm{~V}$ to $0.4 \mathrm{~V}$, when we applied the potential of $-0.1 \mathrm{~V}$, the current is stable all the time. Under this potential, the interference of other substances that reduced at large negative potential could be decreased to the minimal. 


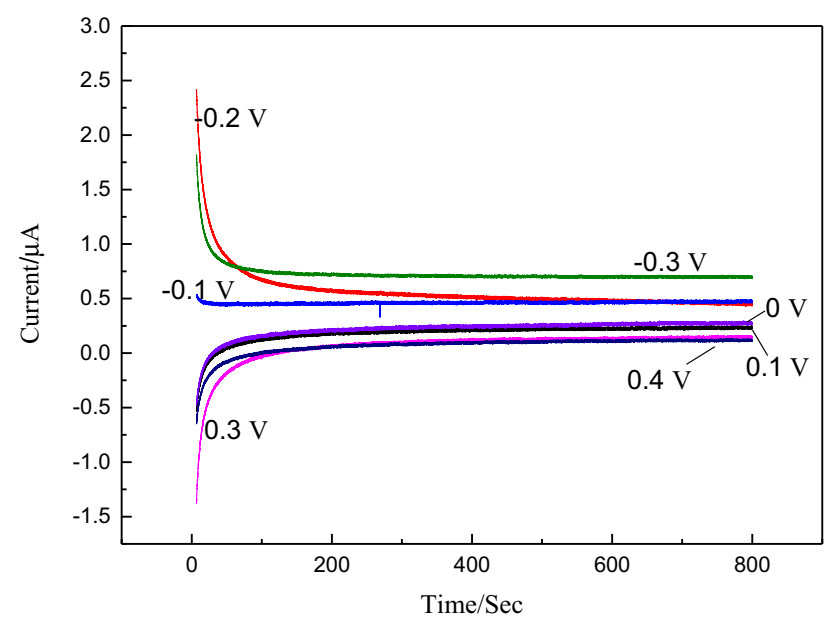

Figure 4. Amperometric curves that were obtained by detecting $\mathrm{H}_{2} \mathrm{O}_{2}$ with a series of applied potential $(-0.3 \mathrm{~V}$, $-0.2 \mathrm{~V},-0.1 \mathrm{~V}, 0 \mathrm{~V}, 0.1 \mathrm{~V}, 0.3 \mathrm{~V}, 0.4 \mathrm{~V})$ in $\mathrm{pH} 7.0 \mathrm{PBS}$ buffer solution.

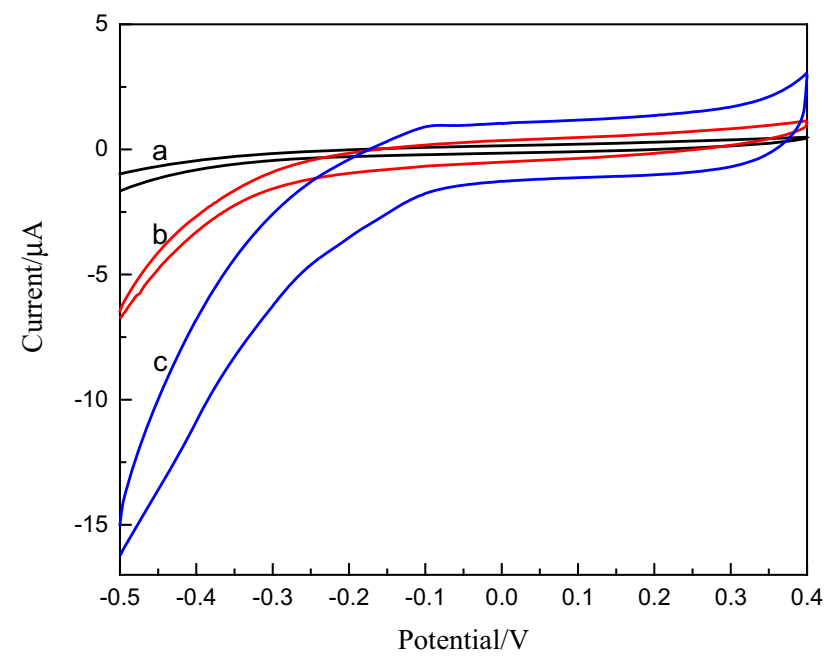

Figure 5. $\mathrm{CV}$ s toward $5 \mu \mathrm{M} \mathrm{H}_{2} \mathrm{O}_{2}$ at different modified electrodes: (a) bare GCE, (b) rGO/GCE, (c) HRP-AP/rGO/ GCE in a pH 7.0 PBS buffer solution.

\subsection{Electrochemical response of the HRP-AP/rGO/ GCE to $\mathrm{H}_{2} \mathrm{O}_{2}$}

$\mathrm{CV}$ measurements of the bare GCE, $\mathrm{rGO} / \mathrm{GCE}$, and HRP-AP/rGO/GCE were carried out as shown in Figure 5. The reductive current of $\mathrm{H}_{2} \mathrm{O}_{2}$ in a $\mathrm{pH}$ 7.0 PBS buffer solution increased according to the sequence of GCE, rGO/GCE, and HRP-AP/rGO/GCE. The results showed HRP had immobilized the surface of the electrode and had good catalytic activity for $\mathrm{H}_{2} \mathrm{O}_{2}$.

Figure 6 presents the chronoamperometric response of the (a) bare GCE, (b) rGO/GCE, (c) AP/rGO/GCE and (d) HRP-AP/rGO/GCE electrode with successive additions of $\mathrm{H}_{2} \mathrm{O}_{2}$ into $0.1 \mathrm{M}$ PBS at $\mathrm{pH} 7.0$, recorded under a stirred system at the potential of $-0.1 \mathrm{~V}$. A

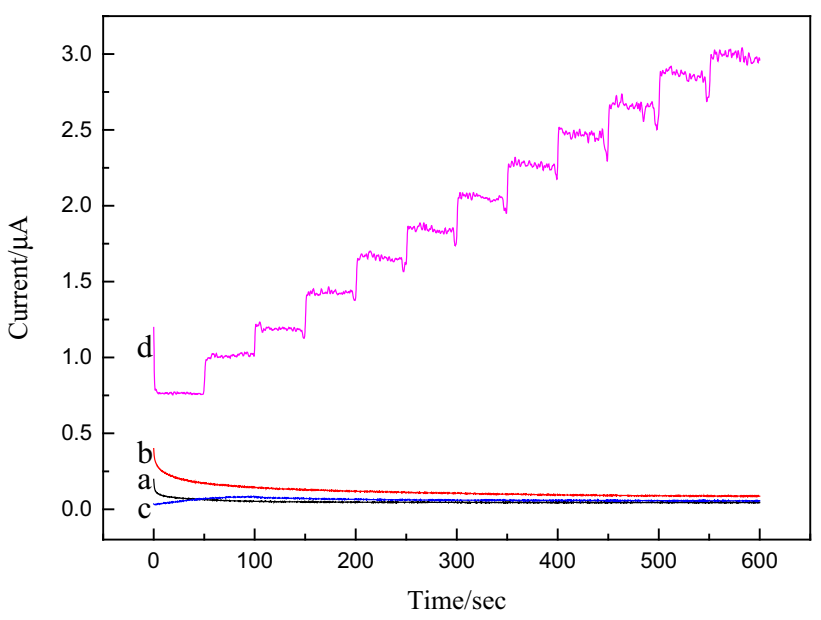

Figure 6. Amperometric response compare of (a) bare GCE, (b) rGO/GCE, (c) AP/rGO/GCE and (d) HRP-AP/rGO/ $\mathrm{GCE}$ at $-0.1 \mathrm{~V}$ upon successive additions of $0.5 \mathrm{mM} \mathrm{H}_{2} \mathrm{O}_{2}$ into 0.1 M PBS at $\mathrm{pH}$ 7.0.

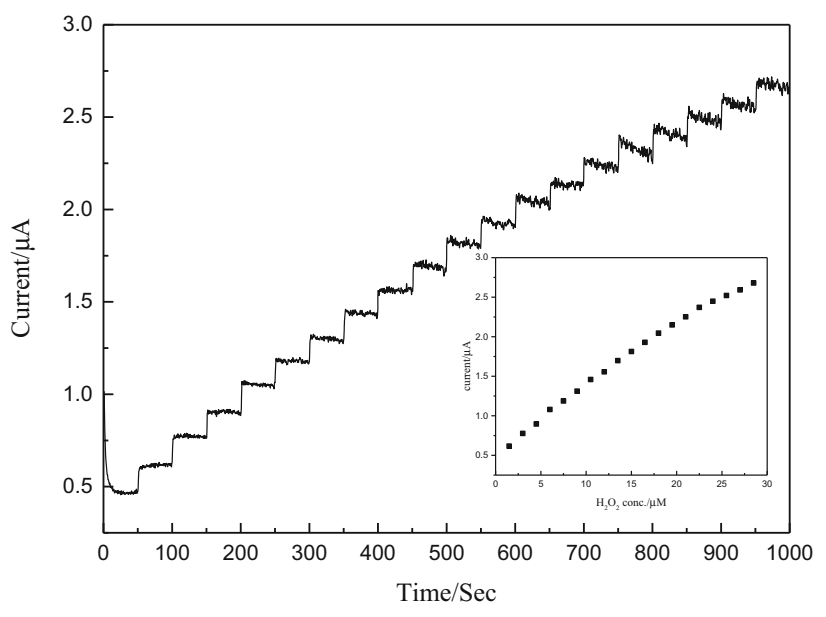

Figure 7. Amperometric response of the HRP-AP/rGO/ GCE in 0.1 M PBS (pH 7.0) at an applied potential of $-0.1 \mathrm{~V}$ upon successive injection of $\mathrm{H}_{2} \mathrm{O}_{2}$ (Inset: the corresponding calibration plot of amperometric response toward $\mathrm{H}_{2} \mathrm{O}_{2}$ ).

gradual increase in the reduction current of $\mathrm{H}_{2} \mathrm{O}_{2}$ was observed on HRP-AP/rGO/GCE with stepped increasing of $\mathrm{H}_{2} \mathrm{O}_{2}$ concentration in $\mathrm{PBS}$, indicating that HRP in the structure of the sensor can electrochemically catalyze the reduction of $\mathrm{H}_{2} \mathrm{O}_{2}$. Experiments were also performed by using the bare GCE, rGO/GCE, and $\mathrm{AP} / \mathrm{rGO} / \mathrm{GCE}$ as the working electrodes respectively, and no response currents towards $\mathrm{H}_{2} \mathrm{O}_{2}$ were observed. These results indicated that the present sensor has high sensitivity compared with those of other sensors. Furthermore, it can be proved that hybrids of reduced graphene oxide with aminoguanidine-HPR indeed played a role of great significance in the enhancement of the response current. 


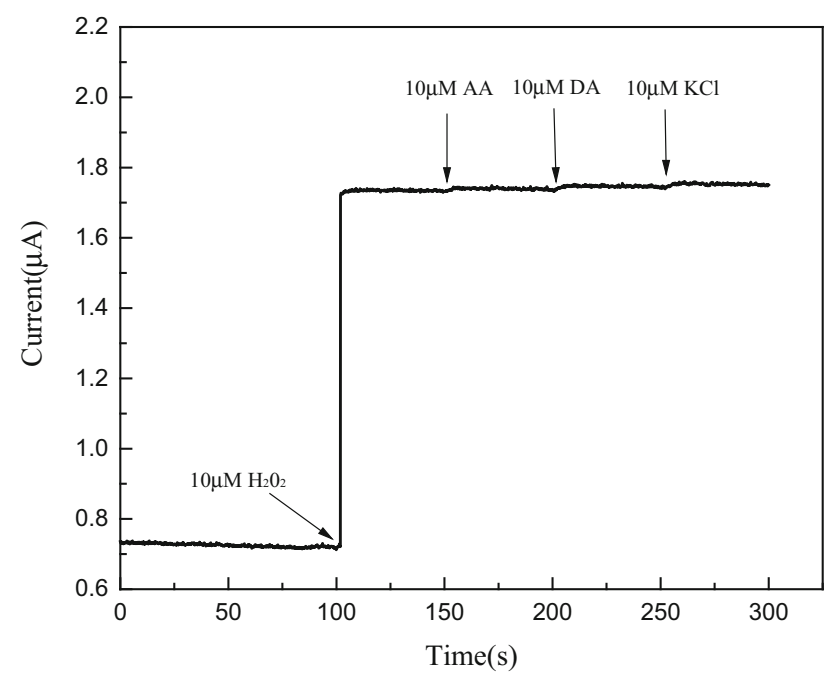

Figure 8. Amperometric response of the HRP-AP/rGO/ GCE to $3 \mu \mathrm{M} \mathrm{H}_{2} \mathrm{O}_{2}$ in the presence of $10 \mu \mathrm{M}$ of $\mathrm{H}_{2} \mathrm{O}_{2}$, ascorbic acid (AA), dopamine (DA) and $\mathrm{KCl}$, respectively.

Figure 7 shows a typical current-time response of the HRP-AP/rGO/GCE at a fixed potential of $-0.1 \mathrm{~V}$ with several sequential additions of $500 \mu \mathrm{M} \mathrm{H} \mathrm{H}_{2} \mathrm{O}_{2}$. The current increased rapidly when $\mathrm{H}_{2} \mathrm{O}_{2}$ was injected into an electrochemical cell containing $0.1 \mathrm{M}$ PBS, and a steady-state current was achieved within several seconds when the current reached $95 \%$ of the steady-state value. This means that such an electrode is highly suitable as an $\mathrm{H}_{2} \mathrm{O}_{2}$ detector. The inset of Figure 7 showed the plot of the response current against $\mathrm{H}_{2} \mathrm{O}_{2}$ concentration. The linear regression equation for the HRP-AP/rGO/GCE biosensor was $I_{\mu \mathrm{A}}=$ $0.6057 \mathrm{C}_{\mu \mathrm{mol} / \mathrm{L}}\left(\mathrm{H}_{2} \mathrm{O}_{2}\right)+0.0768$, and the correlation coefficient was calculated to be $0.996(\mathrm{n}=19)$. The linear detection range was $1.5 \mu \mathrm{M}$ to $28.5 \mu \mathrm{M}$ with a detecting limit of $0.5 \mu \mathrm{M}$. From the comparison of other performance parameters, it can be concluded that the developed electrode exhibits the good characteristics of shorter response time, a wider linear range and a lower detection limit.

\subsection{Stability, reproducibility and selectivity}

In order to investigate the long-term stability of the enzyme sensor, the HRP-AP/rGO/GCE electrode was stored in the refrigerator at $4{ }^{\circ} \mathrm{C}$ and the amperometric response towards $\mathrm{H}_{2} \mathrm{O}_{2}$ were periodically monitored for 7 days. The sensor can retain $87 \%$ to $91 \%$ of its initial current response during testing days. The relative standard derivation (RSD) of its reduction current response was $5.36 \%$ to six parallel experiments, indicating the acceptable repeatability of the proposed modified electrode. All the performances indicate that HRP-AP/rGO can adhere to GCE electrode firmly through amperometric technique. In addition, six electrodes were made independently under the same condition in order to evaluate the reproducibility of the HRP-AP/rGO/GCE electrode. The amperometric responses show a nice reproducibility with a relative standard deviation of $8.1 \%$. The selectivity of the proposed sensing platform was investigated with potential interfering substances including AA (ascorbic acid), DA (dopamine), $\mathrm{KCl}$ (Figure 8). It is clearly seen that only $\mathrm{H}_{2} \mathrm{O}_{2}$ induces an apparent response compared with other interfering substances, suggesting the high selectivity of the HRP-AP/rGO/GCE electrode toward the detection of $\mathrm{H}_{2} \mathrm{O}_{2}$.

\subsection{Application in real samples}

Diluted agave tequilana leaves' juice was used as a biological environment to confirm the application reliability of the HRP-AP/rGO/GCE sensor. For the striking release of $\mathrm{H}_{2} \mathrm{O}_{2}$ in agave, tequilana leaves are correlated with a number of plant-pathogen interactions or environmental stresses and may play an important role in disease resistance. ${ }^{34}$ The samples were diluted 100 times with a PBS solution ( $\mathrm{pH} 7.0)$ and measured by the standard addition method. As listed in Table 1, the recovery for the determination of the $\mathrm{H}_{2} \mathrm{O}_{2}$ sample was $96.1 \%-103.7 \%$ and the RSD was less than $3.8 \%$. Hence, the fabricated $\mathrm{H}_{2} \mathrm{O}_{2}$ sensor presented a suitable application in detecting $\mathrm{H}_{2} \mathrm{O}_{2}$ in physiological samples.

Table 1. Determination results of $\mathrm{H}_{2} \mathrm{O}_{2}$ in real samples $(n=$ $3 \mathrm{mM})$.

\begin{tabular}{lccccc}
\hline Samples & Detected & Added & Found & R.S.D/\% & Recovery/\% \\
\hline 1 & 2.92 & 3.00 & 5.95 & 2.5 & 100.5 \\
2 & 2.77 & 3.00 & 5.98 & 3.0 & 103.7 \\
3 & 2.63 & 3.00 & 5.75 & 3.8 & 102.1 \\
4 & 3.89 & 5.00 & 8.63 & 2.0 & 97.1 \\
5 & 4.22 & 5.00 & 9.02 & 3.1 & 97.8 \\
6 & 3.95 & 5.00 & 8.60 & 3.3 & 96.1 \\
\hline
\end{tabular}




\section{Conclusions}

A novel enzymatic $\mathrm{H}_{2} \mathrm{O}_{2}$ biosensor was successfully fabricated by dispensing HRP-AP/rGO hybrid onto GCE. The modified electrode has excellent electrocatalytic properties confirmed by cyclic voltammetry and alternating current impedance detection. The sensor also exhibited wide linear range, high sensitivity and good stability towards $\mathrm{H}_{2} \mathrm{O}_{2}$ detection under the optimized condition of an applied potential of $-0.1 \mathrm{~V}$ and $\mathrm{pH}$ 7.0. In summary, this easily prepared HRP-AP/rGO/GCE sensor can be a promising amperometric sensor used to monitor the trace amount of $\mathrm{H}_{2} \mathrm{O}_{2}$ released from a living organism.

\section{Acknowledgements}

This work was financially supported by the Natural Science Foundation of Shandong Province, China (Nos. ZR2017MB062, ZR2017BB063 and ZR2015BL014), National Natural Science Foundation of China (Grants 21776298 and 21576280). This work was supported by The Key Project of Joint Fund from National Natural Science Foundation of China and the Government of Xinjiang Uygur Autonomous Region (Grant U1503293), the National Key Research and Development Program of China (Grant 2018YFB06046002), the Key Project of Joint fund from National Nature Science Foundation of China and the Government of Shanxi Province (Grant U1610223), and the Priority Academic Program Development of Jiangsu Higher Education Institutions.

\section{References}

1. Walkey C, Das S, Seal S, Erlichman J, Heckman K and Ghibelli L 2015 Catalytic Properties and Biomedical Applications of Cerium Oxide Nanoparticles Environ. Sci. Nano 233

2. Üzer A, Durmazel S, Erçağ E and Apak R 2017 Determination of hydrogen peroxide and triacetone triperoxide (TATP) with a silver nanoparticles based turn-on colorimetric sensor Sens. Actuat. B 24798

3. Gu X, Wang H and Schultz Z D 2016 Sensing Glucose in Urine and Serum and Hydrogen Peroxide in Living Cells Using a Novel Boronate Nanoprobe Based on Surface-Enhanced Raman Spectroscopy Anal. Chem. 88 7191

4. Zhang L, Hai X, Xia C, Chen X W and Wang J H 2017 Growth of $\mathrm{CuO}$ nanoneedles on graphene quantum dots as peroxidase mimics for sensitive colorimetric detection of hydrogen peroxide and glucose Sens. Actuat. B $\mathbf{2 4 8}$ 374

5. Lin Z, Xiao Y, Yin Y, Hu W, Liu $\mathrm{W}$ and Yang $\mathrm{H}$ 2014 Facile Synthesis of Enzyme-Inorganic Hybrid Nanoflowers and Its Application as a Colorimetric Platform for Visual Detection of Hydrogen Peroxide and Phenol ACS Appl. Mater. Interfaces 13 10775
6. Maji S K, Sreejith S, Mandal A K, Ma X and Zhao Y 2014 Immobilizing gold nanoparticles in mesoporous silica covered reduced graphene oxide: a hybrid material for cancer cell detection through hydrogen peroxide sensing ACS Appl. Mater. Interfaces 16 13648

7. Yang Y C and Tseng W L 2016 1,4-BenzenediboronicAcid-Induced Aggregation of Gold Nanoparticles: Application to Hydrogen Peroxide Detection and BiotinAvidin-Mediated Immunoassay with Naked-Eye Detection Anal. Chem. 885355

8. Zhang T, Gu Y, Li C, Yan X, Lu N and Liu H 2017 Fabrication of novel electrochemical biosensor based on graphene nanohybrid to detect $\mathrm{H}_{2} \mathrm{O}_{2}$ released from living cells with ultrahigh performance ACS Appl. Mater. Interfaces $\mathbf{4 3} 37991$

9. Wu X, Zhang H, Huang K, Zeng Y and Zhu Z 2017 Rose petal and P123 dual-templated macro-mesoporous $\mathrm{TiO}_{2}$ for a hydrogen peroxide biosensor Bioelectrochemistry 120150

10. Isoaho N, Wester N, Peltola E, Johansson L S, Boronat A and Koskinen J 2017 Amorphous carbon thin film electrodes with intrinsic Pt-gradient for hydrogen peroxide detection Electrochim. Acta $\mathbf{2 5 1} 60$

11. Bas S Z, Cummins C, Borah D, Ozmen M and Morris M A 2018 Electrochemical Sensing of Hydrogen Peroxide Using Block Copolymer Templated Iron Oxide Nanopatterns Anal. Chem. 901122

12. Joshi V S, Kreth J and Koley D 2017 Pt-Decorated MWCNTs-Ionic Liquid Composite-Based Hydrogen Peroxide Sensor To Study Microbial Metabolism Using Scanning Electrochemical Microscopy Anal. Chem. 89 7709

13. Jena B K and Raj C R 2011 Enzyme integrated silicate-Pt nanoparticle architecture: A versatile biosensing platform Biosens. Bioelectron. 262960

14. Dey R S and Raj C R 2014 Enzyme-integrated cholesterol biosensing scaffold based on in situ synthesized reduced graphene oxide and dendritic Pd nanostructure Biosens. Bioelectron. 62357

15. Chakraborty S and Retna Raj C 2009 Pt nanoparticlebased highly sensitive platform for the enzyme-free amperometric sensing of $\mathrm{H}_{2} \mathrm{O}_{2}$ Biosens. Bioelectron. 24 3264

16. Bozkurt S, Tosun B, Sen B, Akocak S, Savk A and Ebeoğlugil M F 2017 A hydrogen peroxide sensor based on TNM functionalized reduced graphene oxide grafted with highly monodisperse Pd nanoparticles Anal. Chim. Acta 98988

17. Lu L, Huang X and Qu Y 2011 Effect of the structure of imidazolium cations in $\left[\mathrm{BF}_{4}\right](-)$-type ionic liquids on direct electrochemistry and electrocatalysis of horseradish peroxidase in Nafion films Colloids Surf. $B \mathbf{8 7} 61$

18. Makas Y G, Kalkan N A, Aksoy S, Altinok H and Hasirci N 2010 Immobilization of laccase in $\kappa$ carrageenan based semi-interpenetrating polymer networks J. Biotechnol. 148216

19. Wang J Y, Yu H R, Rui X, Ju X J, Yu Y L and Chu L Y 2013 Alginate/protamine/silica hybrid capsules with ultrathin membranes for laccase immobilization $\mathrm{AlChE}$ J. 59380 
20. Qiu H J, Lu L, Huang X R, Zhang Z H and Qu Y B 2010 Immobilization of horseradish peroxidase on nanoporous copper and its potential applications Bioresour. Technol. 1019415

21. Forde J, Tully E, Vakurov A, Gibson T D and Millner P 2010 Chemical modification and immobilisation of laccase from Trametes hirsuta and from Myceliophtora thermophila Enzyme Microb. Technol. 46 430

22. Martinez-Ortiz J, Flores R and Vazquez-Duhalt R 2011 Molecular design of laccase cathode for direct electron transfer in a biofuel cell Biosens. Bioelectron. 26 2626

23. Polsky R, Harper J C, Dirk S M, Arango D C, And D R W and Brozik S M 2007 Diazonium-Functionalized Horseradish Peroxidase Immobilized via Addressable Electrodeposition: Direct Electron Transfer and Electrochemical Detection Langmuir 23364

24. Matijošytė I, Arends I W C E, Vries S D and Sheldon R A 2010 Preparation and use of cross-linked enzyme aggregates (CLEAs) of laccases J. Mol. Catal. B Enzym. 62 142

25. Wang J 2012 Electrochemical glucose biosensors Progress Chem. 108814

26. Privett B J, Shin J H and Schoenfisch M H 2007 Electrochemical Sensors Anal. Chem. 804499

27. Peng Y, Jiang D, Su L, Zhang L, Yan M and Du J 2009 Mixed monolayers of ferrocenylalkanethiol and encapsulated horseradish peroxidase for sensitive and durable electrochemical detection of hydrogen peroxide Anal. Chem. 819985
28. Akter R, Rahman M A and Rhee C K 2012 Amplified electrochemical detection of a cancer biomarker by enhanced precipitation using horseradish peroxidase attached on carbon nanotubes Anal. Chem. 846407

29. Wang Q, Kromka A, Houdkova J, Babchenko O, Rezek B and Li M 2012 Nanomolar Hydrogen Peroxide Detection Using Horseradish Peroxidase Covalently Linked to Undoped Nanocrystalline Diamond Surfaces Langmuir 28587

30. Gonzálezsánchez M I, Laurenti M, Rubioretama J and Valero E 2011 Fluorescence Decrease of Conjugated Polymers by the Catalytic Activity of Horseradish Peroxidase and Its Application in Phenolic Compounds Detection Biomacromolecules 121332

31. Jiang S and Penner M H 2017 Overcoming Reductant Interference in Peroxidase-Based Assays for Hydrogen Peroxide Quantification J. Agric. Food. Chem. 658213

32. Pang H L, Liu J, Hu D, Zhang X H and Chen J H 2010 Immobilization of laccase onto 1-aminopyrene functionalized carbon nanotubes and their electrocatalytic activity for oxygen reduction Electrochim. Acta 556611

33. Zhou X H, Liu L H, Bai X and Shi H C 2013 A reduced graphene oxide based biosensor for high-sensitive detection of phenols in water samples Sens. Actuat. B Chem. 181661

34. Lima A S, Prieto K R, Santos C S, Paula Valerio H, Garcia-Ochoa E Y, Huerta-Robles A, Beltran-Garcia M J, Mascio P D and Bertotti M 2017 In-vivo electrochemical monitoring of $\mathrm{H}_{2} \mathrm{O}_{2}$ production induced by root-inoculated endophytic bacteria in Agave tequilana leaves Biosens. Bioelectron. 99108 